\section{PHOTOPHONE EXPERIMENTS}

MR. ANDREW jAMIESON, C.E., Principal of the Glasgow Mechanics Institution, sends us an account of the following experiments on the photophone, shown by him at a lecture delivered by him on January 19 , before the Glasgow Philosophical Society, on the history of selenium.

The effects of light and heat on the conductivity of selenium were shown by means of a simple and inexpensive form of "cell" joined up in a Wheatstone's Bridge with a reflecting galvanometer. The cell is constructed in the following way :A piece of plate-glass or of a glass tube of about an inch diameter and about three inches long is chosen, and upon its exterior are tightly wound two separate parallel wires of No. 25 B.W.G., the wires themselves being of copł er covered with silk or cotton. A red-hot iron or poker is then applied to the middle region of the coil of wire so as to burn off the insulating covering of silk

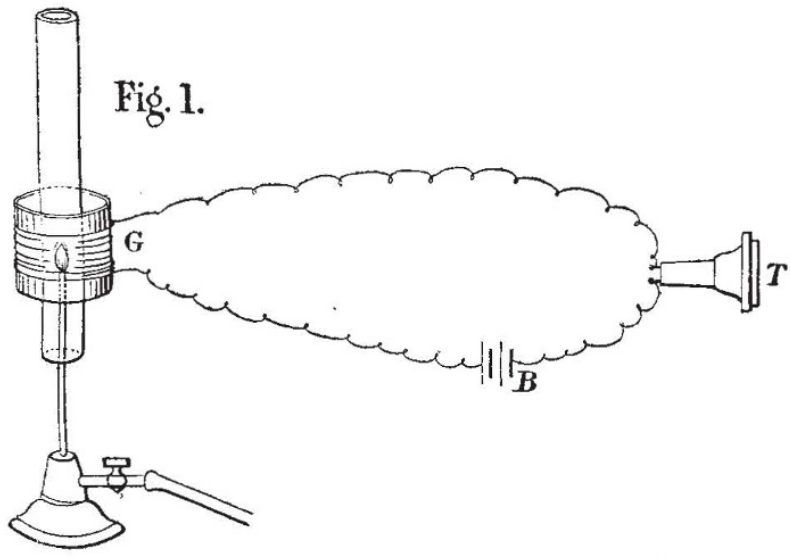

or cotton. The bare wires are cleaned, and the blank cell being raised to the proper temperature, vitreous selenium is rubbed on the wires so as to fill the narrow interspaces left by the removal of the silk covering. The selenium is afterwards annealed in the the usual fashion to render it more highly conductive. One of the cells thus used had resistances of 5740 and 3440 ohms respectively in the dark and in the light; but others have less resistances, one being as small as $500 \mathrm{sm}$ in the dark. The first-named cell (a flat one) was twenty-one days old, and had increased several thousand ohms in that time.

The musical note of a "singing flame" was reproduced in the telephone by means of one of the annular cells thus formed upon a glass tube in the following manner, suggested by Prof. Blyth (Fig. I) :-The cell, C, joined in circuit with a battery, B, and telephone, $T$, was placed outside entirely surrounding the glass tube in which a small gas-jet was " singing." Speech was afterwards reproduced by the arrangement shown in Fig. 2. At the
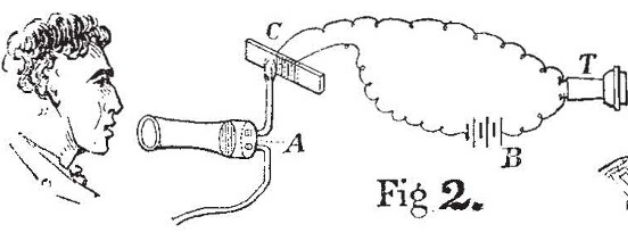

Fig. 2.

back conical mouthpiece which receives the voice is fixed a mem. brane of goldbeater's skin which forms the front of a chamber, A, into which gas is led, and from which a short tube leads to a small gas-jet, in the manner devised by König. Opposite the gas-flame was placed the selenium cell in circuit with a battery of twenty cells and a distant telepbone. There were thus eleven changes going on simultaneously :-

x. Muscular movement of speaker's vocal organs.

2. Vibration of air opposite speaker's mouth.

3. Corresponding vibrations of the thin membrane.

4. Variations of pressure controlling the supply of gas to jet.

5. Hence increase and decrease of gas-flame.

6. Increase and decrease of resistance of the selenium cell.

7. Rise and fall of battery current.

8. Increase and decrease of magnetism in magnet of telephone.
9. To-and-fro movement of telephone disk.

1o. Vibration of air opposite the same.

II. Vibration of drum of ear of listener at the telephone and a sound heard.

Not only the pitch but the tone of the voice was distinctly heard.

\section{THE COFFEE-LEAF DISEASE}

TWO interesting papers on this subject were read at the last meeting ( $3 \mathrm{rd}$ inst.) of the Linnean Society, the one treating of its ravages in India, the other its nature and spread in South America.

In the first Mr. Wm. Bidie, in a letter to Mr. J. Cameron of Bangalore, refers to the Coorg country, situated in the Western Ghats, where European enterprise in coffee has been wholly developed within the last twenty-five years, and no disease was observed till four or five years ago. The author mentions that the disease appears to have been imported from Ceylon by way of Chickmoorloor, a district of Mysore, sixty miles distant from Coorg. It seems worst in impoverished, exposed fields, and least where there is shade and rich soil. A small red insect has been noticed feeding over leaves covered with the pest, but what the insect's relation is to the disease as yet remains unde. termined. Plants grown from Ceylon seed suffer most, fwhile those trees of Coorg origin and growth are least affected. A system of "renovation-pitting" has been successfully tried, a pit being dug at short intervals wherein, after judicious pruning, all the affected leaves are buried, and this precaution seems to check the spread of the disease, particularly among the Coorg coffee-trees.

In the second communication Dr. M. C. Cooke describes and summarises all the data extant up to the present time of the progress of coffee disease in South America. I'lantations in Venezuela, Costa Rica, Bogota, Carácas, and Jamaica have been affected. He discourses on the nature of the blight, and is of opinion that the disease is a complicated one, being himself as yet unprepared to affirm that either the Septoria, the Spharella, or the Stilbum, three so-called different kinds of fungi, or altogether, is the true cause of the disease. At the same time he thinks it possible that none of these forms of fungus are autonomous, and that all may be related to each other as forms or conditions of the same fungus, of which Sphcerella is the highest and most perfect manifestation. He observes that the discoloured spots may be without any visible fungus upon them, and exhibit no trace of mycelium in the tissues, or they may nourish a Septoria, as seen by the Rev. M. J. Berkeley, or a Spharella as found by himself, or finally a species of Stilbum as seen by Prof. Saenx and himself. Further, the Stilbum may occur on the same spot as the perithecia of the Sphcerella, or both perithecia and Stilbum; the one without the other may be found occupying different spots. Mr. Cooke admits that altogether it is difficult satisfactorily to answer the question, What is the cause of this form of coffee disease ?

\section{UNIVERSITY AND EDUCATIONAL INTELLIGENCE}

OXFORD.-Sir William Harcourt announced on Monday that the evidence taken before the Oxford University Commissioners would be laid before Parliament without delay.

CAmbridge. - The first Smith prize has been adjudged to A. R. Forsyth, of Trinity College, Senior Wrangler. R. S. Heath, of Trinity College, Second Wrangler, and A. E. Steinthal, also of Trinity College, Third Wrangler, were equal in the competition for the second prize.

Mr. W. J. Lewis, M.A., of Trinity College, Cambridge, and Fellow of Oriel College, Oxford, has been elected to the Chair of Mineralogy, in the place of the late Prof. Miller, F.R.S. The University is to be congratulated on having secured as Professor of Mineralogy one so competent to take Prof. Miller's place.

Mr. A. Scott is giving demonstrations in Elementary Organic Chemistry at the University Laboratory. Mr. J. F. Walker is lecturing on the same subject at Sidney Sussex College.

Lord Rayleigh is giving a short course on the Unit of Electrical Resistance, and on February $2 \mathrm{I}$ will commence an advanced course of lectures on Sound. Mr. Glazebrook is giving demonstrations on Advanced Electricity and Magnetism, and 